\title{
Inflammatory potential of diet and risk of lymphoma in the European Prospective Investigation into Cancer and Nutrition
}

Marta Solans ${ }^{1,2,3}$, Yolanda Benavente ${ }^{1,4}$, Marc Saez ${ }^{1,2}$, Antonio Agudo ${ }^{5}$, Paula Jakszyn ${ }^{5}$, Pietro

Ferrari $^{6}$, Fatemeh Saberi Hosnijeh ${ }^{7,8}$, Marc Gunter ${ }^{9}$, Inge Huybrechts ${ }^{9}$, Sabine Naudin ${ }^{10}$, Caroline Besson $^{11,12,13}$, Yahya Mahamat-Saleh ${ }^{12,13}$, Marie-Christine Boutron-Ruault ${ }^{12,13}$, Tilman Kühn ${ }^{14}$, Rudolf Kaaks ${ }^{14}$, Heiner Boeing ${ }^{15}$, Cristina Lasheras ${ }^{16}$,Maria-Jose Sánchez ${ }^{17,1}$, Pilar Amiano ${ }^{18,1}$, María Dolores Chirlaque ${ }^{19,1}$, Eva Ardanaz ${ }^{20,21,1}$, Julie A Schmidt ${ }^{22}$, Paolo Vineis ${ }^{23}$, Elio Riboli ${ }^{24}$, Antonia Trichopoulou ${ }^{25}$, Anna Karakatsani ${ }^{25,26}$, Elisavet Valanou ${ }^{25}$, Giovanna Masala ${ }^{27}$, Claudia Agnoli $^{28}$, Rosario Tumino ${ }^{29}$, Carlotta Sacerdote ${ }^{30}$, Amalia Mattiello ${ }^{31}$, Guri Skeie ${ }^{32}$, Elisabete Weiderpass $^{32,33,34,35}$, Mats Jerkeman ${ }^{36}$, Joana Alves Dias ${ }^{37}$ Florentin Späth $^{38}$, Lena Maria Nilsson $^{39}$, Christina C Dahm ${ }^{40}$, Kim Overvad ${ }^{40}$, Kristina Elin Nielsen Petersen ${ }^{41}$, Anne Tjønneland ${ }^{41,42}$,Silvia de Sanjose ${ }^{1,4,43}$, Roel Vermeulen ${ }^{7}$, Alexandra Nieters ${ }^{44}$, Delphine Casabonne $^{1,4}$

1. Centro de Investigación Biomédica en Red: Epidemiología y Salud Pública (CIBERESP), Madrid, Spain

2. Research Group on Statistics, Econometrics and Health (GRECS), University of Girona, Girona, Spain

3. Epidemiology Unit and Girona Cancer Registry, Catalan Institute of Oncology, Girona, Spain

4. Unit of molecular and genetic epidemiology in infections and cancer, Catalan Institute of Oncology (ICO-IDIBELL), Barcelona, Spain

5. Unit of Nutrition and Cancer. Cancer Epidemiology Research Program, Catalan Institute of Oncology (ICO-IDIBELL), Barcelona, Spain

6. Section of Nutrition and Metabolism, International Agency for Research on Cancer (IARC), Lyon, France

7. Institute for Risk Assessment Sciences, Division of Environmental Epidemiology, Utrecht University, Utrecht, The Netherlands

8. Immunology Department, Erasmus University Medical Center, Rotterdam, The Netherlands

9. Nutritional Epidemiology Group (NEP), International Agency for Research on Cancer (IARC-WHO), Lyon, France

10. Nutritional Methodology and Biostatistics Group, International Agency for Research on Cancer (IARC-WHO), Lyon, France

11. Department of Hematology and Oncology, Hospital of Versailles, Le Chesnay, France 
12. CESP, Fac. de médecine - Univ. Paris-Sud, Fac. de médecine - UVSQ, INSERM, Université Paris-Saclay, Villejuif, France

13. Gustave Roussy, Villejuif, France

14. Division of Cancer Epidemiology, German Cancer Research Center (DKFZ), Heidelberg, Germany

15. Department of Epidemiology, German Institute of Human Nutrition (DIfE) PostdamRehbrücke, Nuthetal, Germany

16. Departament of Functional Biology, Oviedo University, Spain

17. Escuela Andaluza de Salud Pública. Instituto de Investigación Biosanitaria ibs.GRANADA. Granada, Spain

18. Public Health Division of Gipuzkoa, Regional Government of the Basque Country, Donostia, Spain

19. Department of Epidemiology, Murcia Regional Health Council, IMIB-Arrixaca, Murcia, Spain

20. Navarra Public Health Institute, Pamplona, Spain

21. IdiSNA, Navarra Institute for Health Research, Pamplona, Spain

22. Cancer Epidemiology Unit, Nuffield Department of Population Health, University of Oxford, Oxford, United Kingdom.

23. Department of Epidemiology and Biostatistics, MRC-HPA Centre for Environment and Health, School of Public Health, Imperial College London, London, United Kingdom

24. School of Public Health, Imperial College London, London, United Kingdom

25. Hellenic Health Foundation, Athens, Greece

26. Pulmonary Medicine Department, School of Medicine, National and Kapodistrian University of Athens, “ATTIKON” University Hospital, Haidari, Greece

27. Cancer Risk Factors and Life-Style Epidemiology Unit. Institute for Cancer Research, Prevention and Clinical Network - ISPRO, 50141 Florence, Italy

28. Epidemiology and Prevention Unit, Fondazione IRCCS Istituto Nazionale dei Tumori, Via Venezian, Milano, Italy

29. Cancer Registry and Histopathology Department, "Civic - M. P. Arezzo" Hospital, ASP Ragusa, Italy

30. Unit of Cancer Epidemiology, Città della Salute e della Scienza University-Hospital and Center for Cancer Prevention (CPO), Turin, Italy

31. Dipartimento di Medicina Clinica e Chirurgia, Federico II University, Naples, Italy

32. Department of Community Medicine, University of Tromsø, The Arctic University of Norway, Tromsø, Norway

33. Department of Research, Cancer Registry of Norway - Institute of Population-Based Cancer Research, Oslo, Norway 
34. Department of Medical Epidemiology and Biostatistics, Karolinska Institutet, Stockholm, Sweden

35. Genetic Epidemiology Group, Folkhälsan Research Center, and Faculty of Medicine, Helsinki University, Helsinki, Finland

36. Department of Oncology, Skåne University Hospital, Lund, Sweden.

37. Lund University, Department of Clinical Sciences, research group in Nutritional Epidemiology, Lund, Sweden.

38. Department of Radiation Sciences, Oncology, Umeå University, Umeå, Sweden

39. Arctic Research Centre, Umeå University, Umeå, Sweden.

40. Section for Epidemiology, Department of Public Health, Aarhus University, Aarhus, Denmark

41. Danish Cancer Society Research Center, Copenhagen, Denmark

42. Department of Public Health, University of Copenhagen, Denmark

43. PATH, Reproductive Health, Seattle, United States

44. Center for Chronic Immunodeficiency (CCI), Medical Center - University of Freiburg, Faculty of Medicine, University of Freiburg, Freiburg, Germany

\section{Names for PubMed indexing}

Solans, Benavente, Saez, Agudo, Jakszyn, Ferrari, Hosnijeh, Gunter, Huybrechts, Naudin, Besson, Mahamat-Saleh, Boutron-Ruault, Kühn, Kaaks, Boeing, Lasheras, Sánchez, Amiano, Chirlaque, Ardanaz, Schmidt, Vineis, Riboli, Trichopoulou, Karakatsani, Valanou, Masala, Agnoli, Tumino, Sacerdote, Mattiello, Skeie, Weiderpass, Jerkeman, Alves Dias, Späth, Nilsson, Dahm, Overvad, Petersen, Tjønneland, de Sanjose, Vermeulen, Nieters, Casabonne

\section{Corresponding author}

Delphine Casabonne, Unit of Infections and Cancer. Cancer Epidemiology Research Programme. IDIBELL. Catalan Institute of Oncology. Av. Gran Via de l'Hospitalet 199-20308908 L'Hospitalet de Llobregat, Spain E-mail: dcasabonne@iconcologia.net

Short running head: Inflammatory potential of diet and lymphoma risk 


\section{$\underline{\text { Sources of support }}$}

European Commission (DG-SANCO), International Agency for Research on Cancer, Danish Cancer Society (Denmark), Ligue Contre le Cancer, Institut Gustave Roussy, Mutuelle Generale de l'Education Nationale, Institut National de la Sante et de la Recherche Medicale (INSERM) (France), German Cancer Aid, German Cancer Research Center (DKFZ), Federal Ministry of Education and Research (BMBF), Deutsche Krebshilfe, Deutsches Krebsforschungszentrum and Federal Ministry of Education and Research (Germany), the Hellenic Health Foundation (Greece), Associazione Italiana per la Ricerca sul Cancro-AIRC-Italy and National Research Council (Italy), Dutch Ministry of Public Health, Welfare and Sports (VWS), Netherlands Cancer Registry (NKR), LK Research Funds, Dutch Prevention Funds, Dutch ZON (Zorg Onderzoek Nederland), World Cancer Research Fund (WCRF), Statistics Netherlands (The Netherlands); Grant number: ERC2009-AdG 232997; Grant sponsors: Nordforsk, Nordic Centre of Excellence programme on Food, Nutrition and Health (Norway); Grant sponsor: Spanish Ministry of Economy and Competitiveness - Carlos III Institute of Health cofunded by FEDER funds/European Regional Develpment Fund (ERDF) - a way to build Europe, Grant numbers: [PI13/00061 (to Granada), PI13/01162 (to EPIC-Murcia, Regional Governments of Andalucia, Asturias, Basque Country, Murcia and Navarra), PI17/01280 and PI14/01219 (to Barcelona), Centro de Investigación Biomédica en Red: Epidemiología y Salud Pública (CIBERESP, Spain)]; Grant sponsor: AGAUR; Grant number (2017SGR1085); Grant sponsor: ISCIII RETIC; Grant number: RD06/0020 (Spain); Grant sponsors: Swedish Cancer Society, Swedish Research Council and County Councils of Skåne and Vasterbotten (Sweden) and Cancer Research UK; Grant numbers: 14136 (to EPIC-Norfolk), C570/A11692, C570/A16491 and C8221/A19170 (to EPIC-Oxford); Grant sponsor: Medical Research Council; Grant numbers: 1000143 (to EPICNorfolk), MR/M012190/1 (to EPIC-Oxford, UK).

This study is listed on the ISRCTN registry with the study ID ISRCTN12136108.

Availability of data and materials: For information on how to submit an application for gaining access to EPIC data and/or biospecimens, please follow the instructions at http://epic.iarc.fr/access/index.php.

Conflict of Interest Statement: None of the authors declared a conflict of interest.

Abbreviations list 
BMI: body mass index

CLL/SLL: chronic lymphocytic leukemia, small lymphocytic lymphoma

DII: dietary inflammatory index

DLBCL: diffuse large B-cell lymphoma

EPIC: European Prospective Investigation into Cancer and Nutrition

FL: follicular lymphoma

HL: Hodgkin lymphoma

ISD: inflammatory score of diet

MM/PCN: multiple myeloma/plasma cell neoplasm

NHL: Non-Hodgkin lymphoma

WCRF/AICR: World Cancer Research Fund/American Institute for Cancer Research.

Word count:

- Abstract: 244 words

- Text: 3,246 words

- Tables and figures: 3 tables

- Online Supplemental material: 2 tables and 1 figure 


\section{Abstract}

2 Background: Chronic inflammation plays a critical role in lymphomagenesis and several dietary

3 factors seem to be involved in the regulation of this process.

4 Objective: The aim of the current study was to assess the association between the inflammatory 5 potential of the diet and the risk of lymphoma and its subtypes in the European Investigation into

6 Cancer and Nutrition (EPIC) study.

7 Design: The analysis included 476,160 subjects with an average follow-up of 13.9 years, during 8 which 3,136 lymphomas (135 Hodgkin lymphoma (HL), 2,606 non-Hodgkin lymphoma (NHL) 9 and 395 NOS) were identified. The dietary inflammatory potential was assessed by means of an 10 inflammatory score of the diet (ISD), calculated using 28 dietary components and their 11 corresponding inflammatory weights. The association between the ISD and lymphoma risk was 12 estimated by hazard ratios (HR) and 95\% confidence intervals (CI) calculated by multivariable 13 Cox regression models adjusted for potential confounders.

14 Results: We did not find a statistically significant association between the ISD and overall 15 lymphoma. Among lymphoma subtypes, positive associations between the ISD and mature B-cell 16 NHL (HR for a 1-SD increase: 1.07 (95\%CI: 1.01; 1.14), p-trend=0.03) were observed. No 17 statistically significant associations where found among other subtypes; however, albeit with 18 smaller number of cases, high HR were observed for HL (HR for a 1 SD increase $=1.22$ (95\% CI $190.94 ; 1.57)$, p-trend 0.06).

20 Conclusions: Our findings suggest that low-grade chronic inflammation induced by the diet may 21 be modestly associated with risk of B-cell lymphoma subtypes. Further studies are warranted to 22 confirm these findings.

23 Key words: Chronic inflammation; inflammatory score of the diet; lymphoma; nutrition; prospective studies 


\section{Introduction}

Lymphomas are a heterogeneous group of malignancies that arise from the lymphatic system. Their etiology remains largely unknown, with few well-established risk factors including immunosuppression, certain infections and other chronic inflammatory conditions(1-3). In addition, several individual dietary factors have been linked to lymphoma risk, although to the date, no conclusive associations have been reported(4).

Chronic inflammation is known to play an important role in carcinogenesis(5) and several lines of evidence suggest that this process may be influenced by specific dietary factors(6). Indeed, several food components have an impact on blood concentrations of inflammatory markers, including cytokines, chemokines, acute-phase proteins, soluble adhesion molecules and cytokine receptors(6,7). Recently, promising tools have emerged to assess the inflammatory potential of diet - the dietary inflammatory index (DII)(8) and the inflammatory score of diet (ISD)(9), scores combining the intake of dietary constituents and their association with well-known inflammatory markers. Epidemiological studies have assessed the association between the DII/ISD and several solid neoplasms, such as breast(10), gastric(9), oral and pharyngeal(11), renal(12) or colorectal(13) cancers. To date, however, evidence on haematological malignancies is scarce, with no prospective data and only two case-control studies reporting a positive association between a pro-inflammatory diet and NHL(14) and no associations for HL(15).

The aim of this study is to investigate the association between the inflammatory potential of diet, measured by means of the ISD, and lymphoma risk within the European Prospective Investigation into Cancer and Nutrition (EPIC) population. 


\section{Methods}

\section{Study population}

EPIC is an ongoing prospective cohort study involving 23 centers from ten European countries (Denmark, France, Germany, Greece, the Nederland’s, Italy, Norway, United Kingdom, Spain and Sweden). The rationale, full methods and study design have been described previously(16,17). In brief, 521,324 subjects, mostly aged 30 to 70 years, were recruited between 1992 and 2000. Written informed consent was provided by all participants. The ethical review boards from the International Agency for Research on Cancer (IARC) and from all local centers approved the study. Prior to analysis, the following exclusions were made: participants with a prevalent cancer $(n=25,184)$, with missing follow-up information $(n=4,148)$, with incomplete/ no dietary information $(n=$ $6,259)$, or those in the highest and lowest $1 \%$ of the distribution for the ratio of energy intake to estimate energy requirement $(n=9,573)$. Thus, our final study population included 476,160 EPIC participants among whom 3,136 incident lymphoma cases occurred during an average follow-up of 13.9 years.

\section{Data collection}

Validated country-specific questionnaires were used to record the usual diet during the previous year(17,18); namely through quantitative or semi-quantitative food frequency questionnaires (FFQs) (administered through a personal interview or self-administered), although few countries used semi-quantitative FFQs combined with a food record. Lifestyle questionnaires were used to obtain information on sociodemographic characteristics, physical activity, reproductive history, use of oral contraceptives and hormone replacement therapy, medical history and alcohol and tobacco consumption. Anthropometric measures were also ascertained at recruitment. 
Exposure assessment: ISD

The inflammatory potential of diet was assessed using the ISD. Its scoring system has been described elsewhere(9). In brief, 28 food parameters (e.g. carbohydrates, fats, vitamins or flavonoids) available in the EPIC databases for all centers were selected. The intake of each food parameter was standardized using the mean and standard deviation of our study population (Supplementary material, Table S1). These z-scores were then converted to percentile scores to avoid the right skewness of data, and then centred on 0 by doubling each percentile score and subtracting 1 . The centred percentile values were then multiplied by its respective inflammatory weight, also used to construct the DII, obtained after a literature review according to the pro- or anti-inflammatory effect of the food parameter, the level of evidence of the studies and the number of articles reviewed (8). The food parameter-specific inflammatory score was then summed to obtain the overall ISD for each individual. Overall, the ISD is a relative index that allows categorizing individuals' diets on a continuum from maximally anti-inflammatory (corresponding to lower scores) to maximally pro-inflammatory (higher scores).

The procedure of construct the ISD is similar to the DII(8) with a few modifications. First, we used 28 food parameters instead of the 45 included in the DII (Supplementary material, Table S1). Information on total fats was dismissed because its inflammatory effect is likely to be represented by the weights of all separate components of fats (i.e. saturated, mono-unsaturated, and polyunsaturated fats), and thus, including them in the scoring calculation could imply an overestimation of its inflammatory effect. For the remaining food parameters, information was not available or not specific enough to be used (e.g. type of tea, green/black). Second, we used a different weight for alcohol owing its dose-dependent effect. In the DII, alcohol is considered to be anti-inflammatory (it has a negative weight, -0.278 for all levels of consumption), but this property has only been 
reported in literature for moderate consumers (less than 30-40 g/day). Therefore, we restricted this weight to moderate consumers (Supplementary material, Table S1). Finally, each individual item intake was standardized using the mean and standard deviation (SD) of our study population (Supplementary material, Table S1), whereas the DII used data from a regional worldwide database taken as "referent” population. Given that comparing the inflammatory potential of diet was not the aim of this study, but assessing whether the inflammatory potential of diet was associated with cancer risk, we gave priority to internal validity and used our own population to standardize the intakes of the ISD components.

\section{Follow-up and outcome assessment}

Incident lymphoma cancer cases were identified by population cancer registries for Denmark, Italy, the Netherlands, Norway, Spain, Sweden and the United Kingdom. A combination of methods was used in France, Germany and Greece, as detailed previously(17). Mortality data were also obtained from regional or national mortality registries. The follow-up period was defined from the age at recruitment to the age at first cancer diagnosis, death or last complete follow-up, depending on which occurred first. Censoring dates for the last complete follow-up ranged from June 2008 to December 2013, depending on the EPIC center.

Initially, the diagnosis of lymphoma cases was based on the second revision of the International Classification of Diseases for Oncology (ICD-O-2). Later, all cases were reclassified into the ICD-O-3 using a conversion program available on the web site of the Surveillance Epidemiology and End Results (SEER) program (http://seer.cancer.gov/tools/conversion/ICD02- 3manual.pdf) and involving a pathology expert and experts from the EPIC centers. Because not all ICD-O-2 diagnostics can be 
122 translated unequivocally into the ICD-O-3 classification, we left the respective 123 lymphomas unclassified (not otherwise specified "NOS”) when further detailed 124 specification failed. Finally, the InterLymph Pathology Working Group classification, 125 which is based in the current 2008 WHO classification, was used to categorize lymphoma 126 histologic subtypes(19).

127 In the current analysis, the following groups were considered: Hodgkin lymphoma (HL) 128 and non-Hodgkin lymphoma (NHL); within NHL, mature B-cell lymphoma and mature 129 T/NK-cell lymphoma; and among mature B-cell lymphoma, the following entities: 130 diffuse large B-cell lymphoma (DLBCL) (including Burkitt lymphoma), follicular lymphoma (FL) (all grades), chronic lymphocytic leukemia/small lymphocytic leukemia (CLL/SLL), multiple myeloma/plasma cell neoplasm (MM/PCN), and other B-cell lymphoma (i.e. those cases in which the B-cell lymphoma subtype is unknown or does not fall within the above mentioned subtypes). Other entities were not considered due to small numbers (Table 1). Overall, during an average follow-up of 13.9 years, 3,136 lymphoma cases were diagnosed.

Statistical analysis

Cox proportional hazard models were used to estimate the hazard ratio (HR) and 95\% confidence intervals (CI) to examine the association between the ISD and lymphoma risk.

140 Entry time was defined as age at recruitment and exit time was age at diagnosis (cases), death, or end of follow-up, whichever came first. Two models with two levels of adjustment were used: a basic model, stratified by center, sex and age at recruitment (in 1-year categories), and a multivariable model, further adjusted for body mass index (BMI) $\left(<25,25-30, \geq 30 \mathrm{~kg} / \mathrm{m}^{2}\right)$, total energy intake (continuous, $\mathrm{kcal} /$ day), education level (no formal education, primary school, secondary school, technical or professional training, 


\section{6}

university, unknown [3.6\%]), height (continuous, cm), physical activity level based on the Cambridge Physical Activity Index (inactive, moderately inactive, moderately active, active, unknown [1.9\%]), smoking status (never, former, current and, unknown [2.0\%]), and alcohol intake at recruitment (continuous, g/day).

The ISD was analysed both as a continuous variable (1-standard deviation [SD] increase) and as a categorical variable (in quartiles). The ISD categorical variable was scored from 1 to 4 , and trend tests were calculated on these scores. In addition, we tested for interaction by age, sex, smoking status and alcohol intake by including a cross-product term along with the armed score (continuous) in the multivariable Cox model. The statistical significance of the cross-product term was evaluated using likelihood ratio test.

Sensitivity analyses were performed by repeating main Cox analyses (i) censoring participants and excluding cases with less than two years of follow-up (n=259), (ii) excluding participants without complete data (n=226), and (iii) restricting HL analysis to classical HL cases. Moreover, given that alcohol has been shown to be inversely associated with several lymphoma subtypes(20), we excluded it from the ISD construction to confirm it was not the only element driving the associations found. Schoenfeld residuals were assessed to ensure that the assumptions of proportional hazards were met in all models. Two-sided p-values were reported with statistically significance set at $\mathrm{p}<0.05$. All analyses were performed by using STATA statistical software, version 14 (Stata Corporation, College Station, Texas). 
169 Distributions of all the EPIC participants and of the lymphoma cases by country are 170 displayed in Table 1. The inflammatory potential of diet in the whole cohort, measured 171 by the ISD, had a mean of 0.26 with SD of 1.00 and a ranged from -6.38 (the maximum 172 anti-inflammatory value) to 5.01 (the maximum pro-inflammatory value). Lower ISD 173 means were observed in the UK and Greece whereas higher ISD means were seen in 174 Norway and Sweden.

Baseline characteristics of the study participants according to the ISD are detailed in

Table 2. In general, participants with higher values of the ISD (more pro-inflammatory diet) were more likely to be women, ever smokers, and physically inactive, with a lower education level, alcohol and energy intake compared with those with a lower ISD score (more anti-inflammatory diet).

The association of the inflammatory potential of the diet with lymphoma and its subtypes is presented in Table 3. Overall, the ISD was not associated with risk of lymphoma $\left(\mathrm{HR}_{\mathrm{Q} 4 v \mathrm{QQ} 1}=1.07(95 \% \mathrm{CI}\right.$ 0.93; 1.22, p-trend $=0.34) ; \mathrm{HR}$ for a 1-SD increase $=1.05(95 \%$ CI 1.00; 1.11), p-trend= 0.06). Among lymphoma subtypes, each SD increase in the ISD was associated with a 6\% higher risk of having NHL (95\% CI 1.00; 1.13 , p-trend= 0.04), and within them, there were modest positive associations for mature B-cell NHL (HR for a 1-SD increase $=1.07(95 \%$ CI 1.01; 1.14), p-trend= 0.03) and other B-cell neoplasms $\left(\mathrm{HR}_{\mathrm{Q} 4 \mathrm{vQ} Q 1}=1.54(1.01 ; 2.34), \mathrm{p}\right.$-trend= 0.07$)$. No statistically significant associations 0.08); HR for a 1SD increase= 1.22 (95\% CI 0.94; 1.57), p-trend 0.06). Following the exclusion of non-classical HL $(\mathrm{n}=8)$ risk showed similar results $\left(\mathrm{HR}{ }_{\mathrm{Q}} \mathrm{vs}_{\mathrm{Q} 1}=1.98(95 \%\right.$ CI: 0.99; 3.97), p-trend= 0.09; HR for a 1-SD increase= 1.23 (95\% CI: 0.94; 1.59), ptrend $=0.13)$. Neither age, sex, smoking status nor alcohol consumption modified the 
associations of the ISD and risk of lymphoma, HL, NHL or mature B-cell NHL (Supplementary material, Table S2). Likewise, no statistically significant interactions were detected for the rest of mature B-cell NHL subtypes (data not shown). Similarly, no significant differences in the association of lymphoma and its subtypes were observed by country, with the exception of DLBCL (Supplementary material, Figure S1).

In sensitivity analyses, excluding alcohol from the ISD construction, excluding first 2 years of follow-up or those individuals with no information on adjustment variables from the analyses did not substantially alter the observed associations (data not shown).

\section{Discussion}

In this large European prospective study, the inflammatory potential of diet, measured by means of the ISD was not associated with overall lymphoma risk and showed a modest association with B-cell lymphoma subtypes.

In the recently released Third Expert Report by the WCRF/AICR(21), the Panel did not make any judgements regarding the causality of associations between specific dietary factors and lymphoid neoplasms. During the last decades, most nutritional epidemiological studies have shifted to dietary pattern analyses, which represent a broader picture of subject's diet, and may thus be more predictive of disease risk than individual foods or nutrients(22). Among them, the ISD and DII represents a promising tool to evaluate a set of dietary exposures with cumulative and interactive effects on both low-grade inflammation and health outcomes(8). While it has been largely studied in solid neoplasms(9-13,23,24), studies on hematological malignancies are utterly scarce, mostly arising from case-control studies restricted to NHL patients without detailed information for specific subtypes. 
218 To the best of our knowledge, this is the first prospective study to investigate the link 219 between the inflammatory potential of diet and risk of lymphoma and its subtypes. Our 220 results are in line with those reported in a multicenter case-control Italian study with 536 221 NHL cases and 934 matched controls(14). The adjusted odds ratio (OR) comparing the 222 highest to the lowest quartile of the DII for NHL was 1.61 (95\% CI: 1.07; 2.43); p trend= 223 0.01)) and when analyses were carried out using continuous DII, the OR for 1-unit increment in the score was 1.14 (95\% CI 1.02; 1.27). Stratified analyses revealed stronger associations between DII and NHL among males and an association between a proinflammatory diet and DLBCL was also reported. By contrast, no associations between the DII and HL ( $n=179)$ were reported in the same case-control study(15). However, although the DII and ISD have been shown to highly correlate in the EPIC population (Pearson's correlation coefficient: 0.91; p-value<0.001)(9), data from both studies cannot be directly compared with ours, since they are based upon different indexes and study designs. In addition, the Italian case-control study lacked information on potential confounders (e.g. BMI or physical activity) as well as on NHL entities other than DLBCL or FL. In the EPIC study, a positive association between the ISD and other B-cell neoplasms (which included Burkitt lymphoma, hairy cell leukemia, lymphoplasmatic lymphoma, mantle cell lymphoma, marginal zone lymphoma, primary effusion lymphoma, and B-cell prolymphocytic lymphoma) was observed, but unfortunately a limited sample size did not allow further specific subtype analyses. Thus, more prospective studies with larger sample size and with detailed lymphoma classification schemes are needed to shed light into this observed relationship.

The role of inflammation, mediated by dietary factors, in the pathogenesis of lymphoma has a strong biological plausibility. Certain autoimmune and chronic inflammatory conditions characterized by severe immune dysregulation such as immunosuppression, 
243 Sjögren's syndrome, systemic lupus erythematosus, and rheumatoid arthritis have been 244 established as strong risk factors for lymphoma(1,2,25). In addition, several infectious 245 agents have been specifically linked to certain subtypes of lymphoma, including the 246 Human immunodeficiency virus, Epstein-Bar virus (EBV), human T-cell lymphotrophic

247 virus-1, human herpes virus-8, and hepatitis C virus, and the bacteria Helicobacter pylori, 248 Borrelia burgdorferi ,Chlamydia psittaci and Campylobacter jejunei(1-3,25). Most of these agents are believed to exert their lymphomagenic mechanisms primarily or partially through chronic immune stimulation(2,3,25). In particular for HL, it is widely believed that its clinical and histological features are primarily due to the effects of a plethora of cytokines and chemokines produced by Reed-Sternberg cells and their surrounding cellular infiltrate in response to inflammatory signals triggered by etiological factors such as $\mathrm{EBV}(26)$. Moreover, it is unclear whether subclinical immunologic perturbations influence lymphoma risk. However, recent studies within general population cohorts incorporating serologic measurements of cytokines, chemokines, and other immune markers have provided important evidence supporting a role for subtle immunologic effects in lymphomagenesis(27-36). The modest associations between the ISD and B-cell lymphoma subtypes suggest that inflammation induced by diet may be also implied in this process and merit further research.

Incidence of lymphoid neoplasms exhibits a marked geographical variability, with the highest incidence rates in western countries, and the lowest found in Asia and Eastern Europe $(37,38)$. In addition, incidence patterns of both HL and NHL vary with migration and nativity, suggesting an influence of acculturation on lymphoma risk $(39,40)$. Indeed, markedly lowered rates of lymphoid malignancies among Asians relative to other racial/ethnic groups in the United States and among foreign-born Asians compared to 
268

269

270

271

272

lymphomagenic processes, but it is still unclear whether this protection relies genetic, environmental differences or a combination. In addition, a Western dietary pattern, characterized by higher intakes of red and processed meats, sweets, desserts, French fries, and refined grains, has been positively associated with inflammatory biomarkers(41). Thus, a westernization of diet, characterized by the inclusion of foods and nutrients with a pro-inflammatory profile, could partly explain these incidence trends.

Limitations of our study should be considered when interpreting the results, including potential measurement errors derived from dietary questionnaires, which could lead to systematic and random errors when estimating the ISD. Although our adjustment for total energy intake and exclusion of subjects with implausible diets (those in the highest and lowest $1 \%$ of the distribution of the ratio between energy intake and estimated energy requirement) would partly remove some of these errors $(42,43)$ we cannot rule out that they have modified risk estimates. However, since dietary information was collected on healthy individuals at the beginning of the study, measurement errors would be expected to be non-differential and thus, their effect would most likely dilute the true association. In addition, we were unable to take into account any possible changes in dietary and lifestyle habits over time. In particular, cases might have modified their diet during the early pre-diagnostic period of the disease, although sensitivity analyses excluding incident cases diagnosed in the first 2 years of follow-up did not alter the association. Moreover, despite adjusting for multiple lymphoma risk factors, residual confounding cannot be dismissed. In addition, because of the high number of comparisons performed, we cannot exclude chance findings. Finally, we lacked of information on the usual consumption of anti-inflammatory drugs or supplements, nor was information collected on foods preserved by salting or sodium intake; all these factors could have influenced the inflammatory potential of diet. Similarly, information on several parameters 
considered in the DII was not available or not specific enough to be used (i.e type of tea, green/black). However, a study reported that seven components explained $91 \%$ of the inter-individual variance in DII(44); all of them included in the ISD, and therefore we can assume that the exclusions made have not had a major impact in the estimation of the inflammatory potential of diet.

Among the strengths of our study are its prospective design and high statistical power, owing to a large number of cases, an accurate case-ascertainment, and the ability to carry out specific analyses according to lymphoma subtypes. The latter is particularly relevant since there is growing evidence that lymphoma subtypes have different pathological and epidemiological features(1). In addition, its multi-centric European design allowed the inclusion of a geographically diverse population, covering a wide range of dietary intakes and lifestyle habits.

In summary, our results suggest that a pro-inflammatory diet may be modestly associated with B-cell lymphomas. Further research including biomarkers of inflammation together with the inflammatory potential of the diet would help to better understand the mechanisms underlying the role of diet-related inflammation and lymphomagenesis for these lymphoma subtypes.

Acknowledgments: We thank all participants of the EPIC study. We thank Catalina Bonet for data management support and Bertrand Hémon at IARC for his valuable work and technical support with the EPIC database.

Conflict of Interest Statement: None of the authors declared a conflict of interest.

Authors' Contribution: DC designed and conducted the research, contributed to the data analysis and manuscript writing, and had primary responsibility for the final content of the manuscript. MSo designed and conducted the research, performed the statistical analysis, wrote the manuscript, and had primary responsibility for the final content of the manuscript. YB, AA, 
319 PJ contributed to the data analysis and YB contributed to manuscript writing. MSa contributed to 320 the statistical analysis. ER is the overall coordinator of the EPIC study. All authors contributed to 321 recruitment, data collection and acquisition, biological sample collection, and follow-up and/or 322 management of the EPIC cohort and to the interpretation of the present findings and approval of 323 the final version of the manuscript for publication. 


\section{References}

1. Morton LM, Slager SL, Cerhan JR, Wang SS, Vajdic CM, Skibola CF, Bracci PM, de Sanjose S, Smedby KE, Chiu BCH, et al. Etiologic heterogeneity among non-Hodgkin lymphoma subtypes: the InterLymph Non-Hodgkin Lymphoma Subtypes Project. J Natl Cancer Inst Monogr. United States; 2014;2014:130-44.

2. Smedby KE, Askling J, Mariette X, Baecklund E. Autoimmune and inflammatory disorders and risk of malignant lymphomas--an update. J Intern Med. England; 2008;264:514-27.

3. Smedby KE, Ponzoni M. The aetiology of B-cell lymphoid malignancies with a focus on chronic inflammation and infections. J Intern Med. England; 2017;282:360-70.

4. WCRF. World Cancer Research Fund. Food, Nutrition, Physical Activity, and the Prevention of Cancer: a Global Perspective. 2nd ed. Washington, USA: American Institute for Cancer Research; 2007.

5. Schottenfeld D, Beebe-Dimmer J. Chronic inflammation: a common and important factor in the pathogenesis of neoplasia. CA Cancer J Clin. United States; 2006;56:69-83.

6. Minihane AM, Vinoy S, Russell WR, Baka A, Roche HM, Tuohy KM, Teeling JL, Blaak EE, Fenech M, Vauzour D, et al. Low-grade inflammation, diet composition and health: current research evidence and its translation. Br J Nutr. England; 2015;114:999-1012.

7. Calder PC, Ahluwalia N, Brouns F, Buetler T, Clement K, Cunningham K, Esposito K, Jonsson LS, Kolb H, Lansink M, et al. Dietary factors and lowgrade inflammation in relation to overweight and obesity. Br J Nutr. England; 2011;106 Suppl:S5-78.

8. Shivappa N, Steck SE, Hurley TG, Hussey JR, Hebert JR. Designing and developing a literature-derived, population-based dietary inflammatory index. Public Health Nutr. England; 2014;17:1689-96. 
9. Agudo A, Cayssials V, Bonet C, Tjonneland A, Overvad K, Boutron-Ruault M-C, Affret A, Fagherazzi G, Katzke V, Schubel R, et al. Inflammatory potential of the diet and risk of gastric cancer in the European Prospective Investigation into Cancer and Nutrition (EPIC) study. Am J Clin Nutr. United States; 2018;107:607-16.

10. Shivappa N, Sandin S, Lof M, Hebert JR, Adami H-O, Weiderpass E. Prospective study of dietary inflammatory index and risk of breast cancer in Swedish women. Br J Cancer. England; 2015;113:1099-103.

11. Shivappa N, Hebert JR, Rosato V, Garavello W, Serraino D, La Vecchia C. Inflammatory potential of diet and risk of oral and pharyngeal cancer in a large case-control study from Italy. Int J cancer. United States; 2017;141:471-9.

12. Shivappa N, Blair CK, Prizment AE, Jacobs DRJ, Hebert JR. Dietary inflammatory index and risk of renal cancer in the Iowa Women's Health Study. Eur J Nutr. Germany; 2018;57:1207-1213.

13. Shivappa N, Prizment AE, Blair CK, Jacobs DRJ, Steck SE, Hebert JR. Dietary inflammatory index and risk of colorectal cancer in the Iowa Women's Health Study. Cancer Epidemiol Biomarkers Prev. United States; 2014;23:2383-92.

14. Shivappa N, Hebert JR, Taborelli M, Montella M, Libra M, Zucchetto A, Crispo A, Grimaldi M, La Vecchia C, Serraino D, et al. Dietary inflammatory index and non-Hodgkin lymphoma risk in an Italian case-control study. Cancer Causes Control. Netherlands; 2017;28:791-9.

15. Shivappa N, Hebert JR, Taborelli M, Zucchetto A, Montella M, Libra M, La Vecchia C, Serraino D, Polesel J. Association between dietary inflammatory index and Hodgkin's lymphoma in an Italian case-control study. Nutrition. United States; 2018;53:43-8.

16. Riboli E, Kaaks R. The EPIC Project: rationale and study design. European Prospective Investigation into Cancer and Nutrition. Int J Epidemiol. England; 1997;26 Suppl 1:S6-14.

17. Riboli E, Hunt KJ, Slimani N, Ferrari P, Norat T, Fahey M, Charrondiere UR, Hemon B, Casagrande C, Vignat J, et al. European Prospective Investigation 
into Cancer and Nutrition (EPIC): study populations and data collection. Public Health Nutr. England; 2002;5:1113-24.

18. Margetts BM, Pietinen P. European Prospective Investigation into Cancer and Nutrition: validity studies on dietary assessment methods. International journal of epidemiology. England; 1997. p. S1-5.

19. Turner JJ, Morton LM, Linet MS, Clarke CA, Kadin ME, Vajdic CM, Monnereau A, Maynadie M, Chiu BC-H, Marcos-Gragera R, et al. InterLymph hierarchical classification of lymphoid neoplasms for epidemiologic research based on the WHO classification (2008): update and future directions. Blood. United States; 2010;116:e90-8.

20. Psaltopoulou T, Sergentanis TN, Ntanasis-Stathopoulos I, Tzanninis IG, Tsilimigras DI DM. Alcohol consumption and risk of hematological malignancies: A meta-analysis of prospective studies. Int J cancer. 2018;143:486-95.

21. WRCF. World Cancer Research Fund/American Institute for Cancer Research. Diet, Nutrition, Physical Activity, and Cancer: a Global Perspective. Continuous Update Project Expert Report 2018. Available at dietandcancerreport.org. 2018.

22. Hu FB. Dietary pattern analysis: a new direction in nutritional epidemiology. Curr Opin Lipidol [Internet]. 2002 [cited 2017 Dec 11];13:3-9. Available from: http://www.ncbi.nlm.nih.gov/pubmed/11790957

23. Shivappa N, Bosetti C, Zucchetto A, Montella M, Serraino D, La Vecchia C, Hebert JR. Association between dietary inflammatory index and prostate cancer among Italian men. Br J Nutr. England; 2015;113:278-83.

24. Dugue P-A, Hodge AM, Brinkman MT, Bassett JK, Shivappa N, Hebert JR, Hopper JL, English DR, Milne RL, Giles GG. Association between selected dietary scores and the risk of urothelial cell carcinoma: A prospective cohort study. Int J cancer. United States; 2016;139:1251-60.

25. Smedby KE, Baecklund E, Askling J. Malignant lymphomas in autoimmunity and inflammation: a review of risks, risk factors, and lymphoma characteristics. Cancer Epidemiol Biomarkers Prev. United States; 2006;15:2069-77. 
26. Khan G. Epstein-Barr virus, cytokines, and inflammation: a cocktail for the pathogenesis of Hodgkin’s lymphoma? Exp Hematol. Netherlands; 2006;34:399-406.

27. Purdue MP, Lan Q, Martinez-Maza O, Oken MM, Hocking W, Huang W-Y, Baris D, Conde B, Rothman N. A prospective study of serum soluble CD30 concentration and risk of non-Hodgkin lymphoma. Blood. United States; 2009;114:2730-2.

28. De Roos AJ, Mirick DK, Edlefsen KL, LaCroix AZ, Kopecky KJ, Madeleine MM, Magpantay L, Martinez-Maza O. Markers of B-cell activation in relation to risk of non-Hodgkin lymphoma. Cancer Res. United States; 2012;72:4733-43.

29. Vermeulen R, Hosnijeh FS, Portengen L, Krogh V, Palli D, Panico S, Tumino R, Sacredote C, Purdue M, Lan Q, et al. Circulating soluble CD30 and future risk of lymphoma; evidence from two prospective studies in the general population. Cancer Epidemiol Biomarkers Prev. United States; 2011;20:1925-7.

30. Purdue MP, Hofmann JN, Kemp TJ, Chaturvedi AK, Lan Q, Park J-H, Pfeiffer RM, Hildesheim A, Pinto LA, Rothman N. A prospective study of 67 serum immune and inflammation markers and risk of non-Hodgkin lymphoma. Blood. United States; 2013;122:951-7.

31. Purdue MP, Lan Q, Bagni R, Hocking WG, Baris D, Reding DJ, Rothman N. Prediagnostic serum levels of cytokines and other immune markers and risk of non-hodgkin lymphoma. Cancer Res. United States; 2011;71:4898-907.

32. Gu Y, Shore RE, Arslan AA, Koenig KL, Liu M, Ibrahim S, Lokshin AE, Zeleniuch-Jacquotte A. Circulating cytokines and risk of B-cell non-Hodgkin lymphoma: a prospective study. Cancer Causes Control. Netherlands; 2010;21:1323-33.

33. Saberi Hosnijeh F, Krop EJM, Scoccianti C, Krogh V, Palli D, Panico S, Tumino R, Sacredote C, Nawroly N, Portengen L, et al. Plasma cytokines and future risk of non-Hodgkin lymphoma (NHL): a case-control study nested in the Italian European Prospective Investigation into Cancer and Nutrition. Cancer Epidemiol Biomarkers Prev. United States; 2010;19:1577-84. 
34. Conroy SM, Maskarinec G, Morimoto Y, Franke AA, Cooney R V, Wilkens LR, Goodman MT, Hernadez BY, Le Marchand L, Henderson BE, et al. Non-hodgkin lymphoma and circulating markers of inflammation and adiposity in a nested case-control study: the multiethnic cohort. Cancer Epidemiol Biomarkers Prev. United States; 2013;22:337-47.

35. Berger E, Delpierre C, Hosnijeh FS, Kelly-Irving M, Portengen L, Bergdahl IA, Johansson A-S, Krogh V, Palli D, Panico S, et al. Association between low-grade inflammation and Breast cancer and B-cell Myeloma and Non-Hodgkin Lymphoma: findings from two prospective cohorts. Sci Rep. England; 2018;8:10805.

36. Epstein MM, Rosner B, Breen EC, Batista JL, Giovannucci EL, Magpantay L, Aster JC, Rodig SJ, Bertrand KA, Laden F, et al. Pre-diagnosis plasma immune markers and risk of non-Hodgkin lymphoma in two prospective cohort studies. Haematologica. Italy; 2018; doi: 10.3324/haematol.2017.183236. [Epub ahead of print]

37. Torre LA, Bray F, Siegel RL, Ferlay J, Lortet-Tieulent J, Jemal A. Global cancer statistics, 2012. CA Cancer J Clin. United States; 2015;65:87-108.

38. Chihara D, Ito H, Matsuda T, Shibata A, Katsumi A, Nakamura S, Tomotaka S, Morton LM, Weisenburger DD, Matsuo K. Differences in incidence and trends of haematological malignancies in Japan and the United States. Br J Haematol. England; 2014;164:536-45.

39. Clarke CA, Glaser SL, Gomez SL, Wang SS, Keegan TH, Yang J, Chang ET. Lymphoid malignancies in U.S. Asians: incidence rate differences by birthplace and acculturation. Cancer Epidemiol Biomarkers Prev. United States; 2011;20:1064-77.

40. Evens AM, Antillón M, Aschebrook-Kilfoy B, Chiu BC-H. Racial disparities in Hodgkin’s lymphoma: a comprehensive population-based analysis. Ann Oncol. 2012;23:2128-37.

41. Lopez-Garcia E, Schulze MB, Fung TT, Meigs JB, Rifai N, Manson JE, Hu FB. Major dietary patterns are related to plasma concentrations of markers of inflammation and endothelial dysfunction. Am J Clin Nutr. United States; 2004;80:1029-35. 
42. Slimani N, Kaaks R, Ferrari P, Casagrande C, Clavel-Chapelon F, Lotze G, Kroke A, Trichopoulos D, Trichopoulou A, Lauria C, et al. European Prospective Investigation into Cancer and Nutrition (EPIC) calibration study: rationale, design and population characteristics. Public Health Nutr. England; 2002;5:1125-45.

43. Ferrari P, Kaaks R, Fahey MT, Slimani N, Day NE, Pera G, Boshuizen HC, Roddam A, Boeing H, Nagel G, et al. Within- and between-cohort variation in measured macronutrient intakes, taking account of measurement errors, in the European Prospective Investigation into Cancer and Nutrition study. Am J Epidemiol. United States; 2004;160:814-22.

44. van Woudenbergh GJ, Theofylaktopoulou D, Kuijsten A, Ferreira I, van Greevenbroek MM, van der Kallen CJ, Schalkwijk CG, Stehouwer CDA, Ocke MC, Nijpels G, et al. Adapted dietary inflammatory index and its association with a summary score for low-grade inflammation and markers of glucose metabolism: the Cohort study on Diabetes and Atherosclerosis Maastricht (CODAM) and the Hoorn study. Am J Clin Nutr. United States; 2013;98:153342. 
Table 1. Distribution of lymphoma cases in the EPIC study.

\begin{tabular}{|c|c|c|c|c|c|c|c|c|c|c|c|c|c|c|}
\hline & \multirow[b]{2}{*}{ Total cohort } & \multirow[b]{2}{*}{ Person-years } & \multirow[b]{2}{*}{ Overall } & \multicolumn{3}{|c|}{ Lymphoma subgroups } & \multicolumn{2}{|c|}{ NHL subgroups ${ }^{1}$} & \multicolumn{4}{|c|}{ mature B-cell subgroups } & \multirow[b]{2}{*}{$\begin{array}{l}\text { Other } \\
\text { B-cell }\end{array}$} & \multirow[b]{2}{*}{ ISD mean $^{2}(\mathrm{SD})$} \\
\hline & & & & $\mathrm{NHL}$ & $\mathrm{HL}$ & NOS & $\begin{array}{r}\text { Mature B- } \\
\text { cell }\end{array}$ & $\begin{array}{r}\text { Mature T/ NK- } \\
\text { cell } \\
\end{array}$ & DLBCL & $\mathrm{FL}$ & CLL/SLL & $\mathrm{MM} / \mathrm{PCN}$ & & \\
\hline Denmark & 55,014 & $815,096.8$ & 631 & 538 & 29 & 64 & 506 & 23 & 121 & 78 & 118 & 123 & 66 & $0.20(0.92)$ \\
\hline France & 67,403 & $869,362.5$ & 228 & 216 & 11 & 1 & 205 & 8 & 40 & 44 & 44 & 45 & 32 & $0.11(0.91)$ \\
\hline Germany & 48,557 & $504,479.0$ & 231 & 190 & 13 & 28 & 170 & 12 & 30 & 20 & 39 & 55 & 26 & $0.54(0.84)$ \\
\hline Greece & 26,048 & $281,283.6$ & 62 & 44 & 3 & 15 & 38 & 2 & 3 & 3 & 13 & 15 & 4 & $-0.19(0.95)$ \\
\hline Italy & 44,545 & $630,951.3$ & 298 & 241 & 15 & 42 & 218 & 11 & 38 & 33 & 44 & 73 & 30 & $0.56(0.86)$ \\
\hline Norway & 33,975 & $452,171.1$ & 163 & 147 & 5 & 11 & 129 & 14 & 26 & 31 & 26 & 24 & 22 & $0.97(0.75)$ \\
\hline Sweden & 48,674 & $801,130.2$ & 517 & 381 & 13 & 123 & 344 & 20 & 57 & 48 & 74 & 132 & 33 & $0.77(0.83)$ \\
\hline The Netherlands & 36,539 & $524,670.7$ & 201 & 186 & 7 & 8 & 172 & 10 & 43 & 26 & 41 & 43 & 19 & $0.47(0.76)$ \\
\hline United Kingdom & 75,416 & $1,122,765$ & 564 & 452 & 25 & 87 & 426 & 20 & 95 & 71 & 87 & 115 & 58 & $-0.53(1.00)$ \\
\hline Total & 476,160 & $6,639,857.5$ & 3,136 & 2,606 & 135 & 395 & 2,402 & 130 & 488 & 381 & 537 & 676 & 320 & $0.26(1.00)$ \\
\hline
\end{tabular}

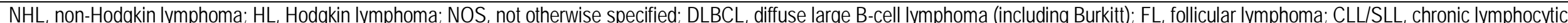

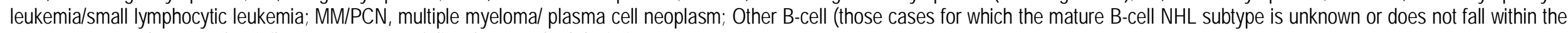
more common subtypes ; ISD, inflammatory score of diet; SD, standard deviation.

1 Three individuals with $\mathrm{NHL}$ without B- or T-cell information.

2ISD: positive values indicate a more pro-inflammatory diet and negative values correspond to a more anti-inflammatory diet 
Table 2. Baseline characteristics of participants in the EPIC study according to the ISD.

\begin{tabular}{|c|c|c|c|c|c|}
\hline & \multirow[b]{2}{*}{ Total cohort } & \multicolumn{4}{|c|}{ ISD } \\
\hline & & $\begin{array}{r}\text { Q1 } \\
\text { (mean }=-1.09, \\
\text { range }-3.52 ;-0.43)\end{array}$ & $\begin{array}{r}\mathbf{Q 2} \\
\text { (mean }=-0.02, \\
\text { range: }-0.43 ; 0.34 \text { ) } \\
\end{array}$ & $\begin{array}{r}\text { Q3 } \\
\text { (mean }=0.68 \\
\text { range: } 0.34 ; 1.02 \text { ) } \\
\end{array}$ & $\begin{array}{r}\text { Q4 } \\
\text { (mean }=1.47 \\
\text { range: } 1.02 ; 2.76) \\
\end{array}$ \\
\hline Total cohort, $\mathrm{n}$ & 476,160 & 119,040 & 119,040 & 119,040 & 119,040 \\
\hline Females (\%) & 70.1 & 64.8 & 67.5 & 71.4 & 76.8 \\
\hline Age at recruitment (mean [SD], years) & $51.2(9.9)$ & $50.7(11.1)$ & $51.5(9.9)$ & $51.5(9.5)$ & $51.2(9.2)$ \\
\hline Energy intake (mean [SD], kcal/day) & $2,075.1(619.2)$ & $2,523.2(640.3)$ & 2,198.1 (540.9) & $1,954.7(468.9)$ & $1,624.3(421.4)$ \\
\hline Alcohol intake (median [25th-75th percentiles], g/day) & $5.3(0.9 ; 14.9)$ & $7.4(1.6 ; 17.9)$ & $6.4(1.3 ; 16.7)$ & $5.3(0.9 ; 14.9)$ & $2.8(0.4 ; 10.6)$ \\
\hline $\mathrm{BMI}\left(\mathrm{mean}[\mathrm{SD}], \mathrm{kg} / \mathrm{m}^{2}\right)$ & $25.4(4.3)$ & $25.4(4.3)$ & $25.4(4.3)$ & $25.4(4.2)$ & $25.5(4.3)$ \\
\hline Height (mean [SD], cm) & $166.0(8.9)$ & $166.9(9.0)$ & $166.4(9.1)$ & $165.8(8.9)$ & $164.9(8.7)$ \\
\hline Smoking status (\% ever) & 49.0 & 45.8 & 48.2 & 49.9 & 52.3 \\
\hline Physical activity (\% inactive) & 21.0 & 19.2 & 20.5 & 21.0 & 23.2 \\
\hline Educational level ( $\% \leq$ primary school) & 30.0 & 23.8 & 28.3 & 31.0 & 36.9 \\
\hline
\end{tabular}

ISD, inflammatory score of diet; Q, quartile; $\mathrm{n}$, total number ; SD: standard deviation; BMI: body mass index. 
Table 3. Association between the ISD and risk of lymphoma and its subtypes in the EPIC study.

\begin{tabular}{|c|c|c|c|c|c|c|c|}
\hline & \multicolumn{7}{|c|}{ ISD } \\
\hline & Q1 & Q2 & Q3 & Q4 & P-trend ${ }^{3}$ & 1-SD increase & P-trend ${ }^{4}$ \\
\hline Lymphoma, n & 784 & 783 & 786 & 783 & & & \\
\hline $\mathrm{HR}^{1}(95 \% \mathrm{Cl})$ & Ref & $0.99(0.89 ; 1.09)$ & $0.99(0.89 ; 1.10)$ & $1.00(0.89 ; 1.11)$ & 1.00 & $1.01(0.97 ; 1.05)$ & 0.56 \\
\hline $\operatorname{HR}^{2}(95 \% \mathrm{Cl})$ & Ref & $1.01(0.91 ; 1.13)$ & $1.04(0.92 ; 1.16)$ & $1.07(0.93 ; 1.22)$ & 0.34 & $1.05(1.00 ; 1.11)$ & 0.06 \\
\hline HL, n & 25 & 35 & 35 & 40 & & & \\
\hline $\mathrm{HR}^{1}(95 \% \mathrm{Cl})$ & Ref & $1.51(0.89 ; 2.55)$ & $1.64(0.96 ; 2.80)$ & $1.99(1.15 ; 3.43)$ & 0.02 & $1.25(1.03 ; 1.52)$ & 0.02 \\
\hline $\mathrm{HR}^{2}(95 \% \mathrm{Cl})$ & Ref & $1.48(0.86 ; 2.57)$ & $1.60(0.88 ; 2.90)$ & $1.90(0.97 ; 3.71)$ & 0.08 & $1.22(0.94 ; 1.57)$ & 0.13 \\
\hline NHL, n & 658 & 659 & 647 & 642 & & & \\
\hline $\mathrm{HR}^{1}(95 \% \mathrm{Cl})$ & Ref & $0.98(0.88 ; 1.10)$ & $0.97(0.86 ; 1.09)$ & $0.98(0.87 ; 1.11)$ & 0.72 & $1.00(0.96 ; 1.05)$ & 0.88 \\
\hline $\mathrm{HR}^{2}(95 \% \mathrm{Cl})$ & Ref & $1.03(0.91 ; 1.15)$ & $1.04(0.92 ; 1.19)$ & $1.10(0.94 ; 1.27)$ & 0.24 & $1.06(1.00 ; 1.13)$ & 0.04 \\
\hline Mature T/ NK-cell, n & 34 & 35 & 31 & 30 & & & \\
\hline $\mathrm{HR}^{1}(95 \% \mathrm{Cl})$ & Ref & $0.93(0.57 ; 1.51)$ & $0.79(0.47 ; 1.33)$ & $0.72(0.42 ; 1.25)$ & 0.20 & $0.99(0.81 ; 1.20)$ & 0.91 \\
\hline $\mathrm{HR}^{2}(95 \% \mathrm{Cl})$ & Ref & $0.86(0.51 ; 1.43)$ & $0.70(0.39 ; 1.25)$ & $0.61(0.31 ; 1.19)$ & 0.12 & $0.99(0.76 ; 1.29)$ & 0.95 \\
\hline Mature B-cell, $n$ & 603 & 608 & 596 & 595 & & & \\
\hline $\mathrm{HR}^{1}(95 \% \mathrm{Cl})$ & Ref & $1.00(0.89 ; 1.12)$ & $0.99(0.88 ; 1.12)$ & $1.02(0.90 ; 1.16)$ & 0.79 & $1.01(0.96 ; 1.06)$ & 0.67 \\
\hline $\mathrm{HR}^{2}(95 \% \mathrm{Cl})$ & Ref & $1.05(0.93 ; 1.19)$ & $1.08(0.94 ; 1.23)$ & $1.15(0.99 ; 1.35)$ & 0.08 & $1.07(1.01 ; 1.14)$ & 0.03 \\
\hline DLBCL, n & 126 & 121 & 118 & 123 & & & \\
\hline $\mathrm{HR}^{1}(95 \% \mathrm{Cl})$ & Ref & $1.00(0.77 ; 1.29)$ & $1.00(0.77 ; 1.31)$ & $1.12(0.85 ; 1.47)$ & 0.46 & $1.05(0.95 ; 1.16)$ & 0.38 \\
\hline $\mathrm{HR}^{2}(95 \% \mathrm{Cl})$ & Ref & $1.03(0.78 ; 1.34)$ & $1.06(0.78 ; 1.42)$ & $1.21(0.86 ; 1.70)$ & 0.29 & $1.09(0.96 ; 1.25)$ & 0.20 \\
\hline $\mathrm{FL}, \mathrm{n}$ & 98 & 95 & 98 & 90 & & & \\
\hline $\mathrm{HR}^{1}(95 \% \mathrm{Cl})$ & Ref & $0.98(0.73 ; 1.31)$ & $1.00(0.74 ; 1.35)$ & $0.91(0.66 ; 1.25)$ & 0.62 & $0.99(0.89 ; 1.11)$ & 0.89 \\
\hline $\mathrm{HR}^{2}(95 \% \mathrm{Cl})$ & Ref & $1.05(0.78 ; 1.43)$ & $1.13(0.81 ; 1.58)$ & $1.10(0.74 ; 1.62)$ & 0.58 & $1.09(0.94 ; 1.27)$ & 0.25 \\
\hline CLL/SLL, n & 129 & 149 & 135 & 124 & & & \\
\hline $\mathrm{HR}^{1}(95 \% \mathrm{Cl})$ & Ref & $1.13(0.89 ; 1.44)$ & $1.05(0.81 ; 1.35)$ & $1.02(0.78 ; 1.34)$ & 0.97 & $1.00(0.91 ; 1.10)$ & 0.99 \\
\hline $\mathrm{HR}^{2}(95 \% \mathrm{Cl})$ & Ref & $1.13(0.88 ; 1.46)$ & $1.07(0.80 ; 1.42)$ & $1.04(0.75 ; 1.45)$ & 0.95 & $1.01(0.89 ; 1.15)$ & 0.88 \\
\hline MM/PCN, n & 170 & 160 & 171 & 175 & & & \\
\hline $\mathrm{HR}^{1}(95 \% \mathrm{Cl})$ & Ref & $0.90(0.72 ; 1.12)$ & $0.94(0.75 ; 1.18)$ & $0.96(0.76 ; 1.21)$ & 0.85 & $0.99(0.91 ; 1.08)$ & 0.84 \\
\hline $\mathrm{HR}^{2}(95 \% \mathrm{Cl})$ & Ref & $0.94(0.75 ; 1.19)$ & $1.02(0.79 ; 1.31)$ & $1.08(0.81 ; 1.45)$ & 0.48 & $1.05(0.93 ; 1.17)$ & 0.43 \\
\hline Other B-cell ,n & 80 & 83 & 74 & 83 & & & \\
\hline $\mathrm{HR}^{1}(95 \% \mathrm{Cl})$ & Ref & $1.05(0.77 ; 1.44)$ & $0.96(0.69 ; 1.34)$ & $1.16(0.83 ; 1.62)$ & 0.51 & $1.03(0.91 ; 1.17)$ & 0.64 \\
\hline $\mathrm{HR}^{2}(95 \% \mathrm{Cl})$ & Ref & $1.18(0.85 ; 1.65)$ & $1.17(0.80 ; 1.69)$ & $1.54(1.01 ; 2.34)$ & 0.07 & $1.16(0.98 ; 1.37)$ & 0.08 \\
\hline $\begin{array}{l}\text { nultiple myeloma/ plasma } \\
\text { nore common subtypes. } \\
\text { Basic model: Cox proport } \\
\text { Multivariate model: Cox } \mathrm{p} \\
\text { otal energy intake, educa } \\
\mathrm{P} \text { value of Cox proportion } \\
\mathrm{P} \text { value of Cox proportion } \\
\\
\text { bold: } \boldsymbol{D}<0.05\end{array}$ & $\begin{array}{l}\text { zard m } \\
\text { nal haz }\end{array}$ & zodel stratified by age & $\begin{array}{l}\text { (in 1-year categories } \\
\text { by age (in 1-year cate }\end{array}$ & $\begin{array}{l}\text { nature B-cell NHL sub } \\
\text { s), center and sex } \\
\text { egories), center and se } \\
\text { lintake. } \\
\text { s to test for lineal tren }\end{array}$ & ex and furth & nown or does not fall & $\begin{array}{l}\text {, diffuse } \\
\text { 1M/PCN, } \\
\text { within the } \\
\text { mass index, }\end{array}$ \\
\hline
\end{tabular}

